\title{
Technical note: Development of multiplex PCR assays for the molecular characterization of Streptococcus uberis strains isolated from bovine mastitis
}

\author{
Dario Calonzi, ${ }^{1}$ Alicia Romano, ${ }^{2}$ Valentina Monistero, ${ }^{3}$ Paolo Moroni, ${ }^{3,4}$ Mario Vittorio Luini, ${ }^{2}$ \\ Filippo Biscarini, ${ }^{1}$ Bianca Castiglioni, ${ }^{1}$ and Paola Cremonesi ${ }^{1 *}$ \\ ${ }^{1}$ Institute of Agricultural Biology and Biotechnology, National Research Council (CNR), Lodi 26900, Italy \\ ${ }^{2}$ Istituto Zooprofilattico Sperimentale della Lombardia e dell'Emilia Romagna (IZSLER), Lodi 26900, Italy \\ ${ }^{3}$ Università degli Studi di Milano, Dipartimento di Medicina Veterinaria, Milan 20133, Italy \\ ${ }^{4}$ Quality Milk Production Services, Animal Health Diagnostic Center, Cornell University, Ithaca, NY 14853
}

\begin{abstract}
Streptococcus uberis is an important causative agent for clinical and subclinical mastitis in dairy cattle. The aim of this study was to develop 2 multiplex PCR assays (mPCR) for the simultaneous detection of virulence factors and housekeeping genes for use when investigating the genetic variability and distribution of Strep. uberis virulence factors. The tuf, cpn60, pauA, sod $A$, sua, oppF, and gap $C$ genes were grouped in assay 1 (mPCR1) and the has $A$, hasB, and hasC genes were included in assay 2 (mPCR2). The detection limits were $11.8 \mathrm{pg}$ and $5.9 \mathrm{pg}$ of DNA for mPCR1 and mPCR2, respectively. The $2 \mathrm{mPCR}$ assays were validated with 56 Strep. uberis strains isolated from mastitis milk samples collected from different bovine herds in northern Italy. Results revealed that gapC and oppF were detected in $98.2 \%$ of the strains, whereas sua and hasC genes were detected in 94.6 and $89.2 \%$ of the strains, respectively. The most common pattern was $g a p C+, o p p F+$, сpn60+, sua+, sodA+, pauA+, tuft, hasA+, hasB+, and $h a s C+$, which appeared in $59 \%$ of the strains analyzed. The molecular assays developed in the present study represent a powerful tool for the evaluation of virulence pattern distribution in Strep. uberis strains associated with intramammary infections.
\end{abstract}

Key words: Streptococcus uberis, virulence factor, mastitis, multiplex PCR

\section{Technical Note}

Mastitis is a common disease in dairy cattle and the cause of important economic losses for the dairy industry (Liang et al., 2017). Among mastitis pathogens, Streptococcus uberis can colonize different dairy

Received April 23, 2019

Accepted July 9, 2019.

*Corresponding author: paola.cremonesi@ibba.cnr.it environments (Zadoks et al., 2005) and is implicated in clinical and subclinical IMI during lactation and the dry period (Reinoso et al., 2011), representing a potential risk factor for dairy cattle. It has been estimated that Strep. uberis is responsible for 14 to $26 \%$ of clinical mastitis cases in Canada, the United States, and the Netherlands, and it is the main cause of clinical mastitis in New Zealand and Australia (Collado et al., 2018). It has also been identified as being responsible for a large part of clinical mastitis in several European countries such as Belgium, Germany, Italy, and the UK (Bradley et al., 2007; Krömker et al., 2014). The control of this environmental microorganism can be particularly problematic (Boonyayatra et al., 2018). Streptococcus uberis has several virulence genes; for example, the hyaluronic acid capsule genes (hasA, hasB, and hasC; Ward et al., 2001), the plasminogen activator A gene (pauA; Rosey et al., 1999), and the Strep. uberis adhesion molecule gene (sua; Almeida et al., 2006). These genes all contribute to making this microorganism contagious, as well as having a role in its pathogenicity. Many studies (Yuan et al., 2014; Perrig et al., 2015; Loures et al., 2017) have shown high prevalence of these virulence genes in Strep. uberis strains harvested from several regions of the world. The pauA and sua genes seem to be highly conserved across Strep. uberis strains (Perrig et al., 2015), and have been chosen as target genes for detection in milk by PCR assays (Gillespie and Oliver, 2004). Other virulence factors such as gap $C$ (Pancholi and Fischetti, 1993), which encodes glyceraldehyde3-phosphate dehydrogenase, or oppF (Smith et al., 2002), which is involved in the acquisition of essential amino acids from milk during bacterial growth, have previously been studied for their association with pathogenesis in IMI. A clear understanding of these virulence genes as key factors for mastitis development is still lacking (Boonyayatra et al., 2018). From previous studies (Perrig et al., 2015; Reinoso et al., 2015), it appears that in any given herd, only a limited group 
of Strep. uberis strains colonize the bovine mammary gland, resulting in cow-to-cow infection, whereas other strains appear to be less suited for this environment (Tassi et al., 2013). Different techniques have been used to discriminate individual strains of Strep. uberis. Random amplified polymorphic DNA (RAPD; Wieliczko et al., 2002), pulsed-field gel electrophoresis (PFGE; Reinoso et al., 2015) and multilocus sequence typing (MLST; Pullinger et al., 2006) have all been developed for epidemiological and genotypic studies. Speciesspecific PCR assay targeting the $16 \mathrm{~S}$ rRNA gene was used by Hassan et al. (2001) to unambiguously detect Strep. uberis from a phenotypically identical species, Strep. parauberis. This PCR protocol had been widely used to identify Strep. uberis isolated from mastitis cases before the genotyping methods listed above. Multiplex PCR ( $\mathbf{m P C R}$ ) is an additional molecular tool for epidemiological studies and rapid characterization of Strep. uberis strains isolated from bovine mastitis milk (Boonyayatra et al., 2018).

The aim of this study was to develop 2 low-cost and fast $\mathrm{mPCR}$ assays for the simultaneous detection of 10 genes. Included, from the Italian dairy herds, were virulence factors and housekeeping genes helpful for investigating the genetic variability of Strep. uberis and the distribution of its virulence factors in isolates. The virulence factors included in these $2 \mathrm{mPCR}$ assays are widely studied (Parin et al., 2017; Boonyayatra et al., 2018) and are thought to represent key factors in the invasion process of mammalian epithelial tissue for Strep. uberis.

To optimize the mPCR protocol, the reference Strep. uberis ATCC 9927 strain (LGC Promochem, Middlesex, UK) was used. The mPCR assays were then validated on 56 isolates from composite subclinical mastitis milk samples. These samples were collected between January 2016 and August 2017 from 12 bovine herds in northern Italy. Those farms were chosen because of their large herd size, a monthly incidence of Strep. uberis mastitis of 5 to $6 \%$, availability of reliable health records, and access to microbiological diagnosis of milk samples at the University of Milan. The samples were collected aseptically and the isolation of Strep. uberis strains was performed by plating $10 \mu \mathrm{L}$ of bovine mastitis milk onto trypticase soy agar (TSA) containing 5\% sheep blood and $0.1 \%$ esculin (bioMérieux, Marcy l'Étoile, France). Plates were then incubated aerobically for 24 to 48 $\mathrm{h}$ at $37^{\circ} \mathrm{C}$. Preliminary identification of Strep. uberis was based on colony morphology, esculin splitting, and catalase testing (National Mastitis Council, 2017). All streptococcal isolates were identified at species level by the API 20 Strep (bioMérieux). Genomic DNA was extracted from pure cultures, as previously described by Cremonesi et al. (2006), without a pretreatment step, using a method based on the combination of a chaotropic agent, guanidium thiocyanate, with silica particles to obtain bacterial cell lysis and nuclease inactivation. The concentration of the purified DNA was determined using NanoDrop 2000 (ThermoFisher Scientific Inc., Waltham, MA) and stored at $-20^{\circ} \mathrm{C}$ until further use. The target genes of Strep. uberis included in the mPCR were gapC, oppF, cpn60, sua, sodA, pauA, tuf, hasA, hasB, and hasC. All details concerning the oligonucleotides, including product size, primer sequences, and GenBank accession numbers, are summarized in Table 1. All primers of this study were designed using Primer 3 software (http:/ /primer3.ut.ee/), except for primer cpn60, which was previously described (Dmitriev et al., 2006). The in silico specificity was checked by using the BLAST software tool (https://blast.ncbi.nlm.nih.gov/Blast .cgi). The primers were synthesized by ThermoFisher Scientific. The oligonucleotides were chosen based on similar melting temperatures to use the same amplification protocol with minimal interactions, resulting in different-sized products distinguishable by agarose gel electrophoresis. Using these criteria, $2 \mathrm{mPCR}$ assays were optimized: $g a p C$, oppF, cpn60, sua, sodA, pauA, and tuf were grouped in MPCR1 and has $A$, hasB, and has $C$ in mPCR2.

Initially, both mPCR assays were set up using genomic DNA extracted from the reference Strep. uberis ATCC 9927 strain. The mPCR assays, prepared in $0.2-\mathrm{mL}$ tubes, were performed in a $25-\mu \mathrm{L}$ volume with sodA primers at $1.6 \mu M$ and all other primers at $0.8 \mu M$ (ThermoFisher Scientific, Milan, Italy), PCR master mix 10× (AccuPrime, Invitrogen, Minneapolis, MN), $1 \mathrm{U}$ of AccuPrime Taq DNA Polymerase (Invitrogen), and $2 \mu \mathrm{L}$ of DNA $(\sim 40 \mathrm{ng} / \mu \mathrm{L})$. Amplifications were carried out in a thermocycler (Applied Biosystems, Foster City, CA) with the following program: $94^{\circ} \mathrm{C}$ for 5 min followed by 30 cycles of $94^{\circ} \mathrm{C}$ for $1 \mathrm{~min}, 56^{\circ} \mathrm{C}$ for $1 \mathrm{~min}, 68^{\circ} \mathrm{C}$ for $1 \mathrm{~min}$, and finally a step of $72^{\circ} \mathrm{C}$ for $7 \mathrm{~min}$. The amplified PCR products were visualized simultaneously by standard gel electrophoresis in a 3\% agarose gel (GellyPhor, Euroclone, Milan, Italy), stained with ethidium bromide $(0.05 \mathrm{mg} / \mathrm{mL}$; Sigma Aldrich, Milan, Italy). A molecular size marker (100-bp DNA ladder; Finnzymes, Espoo, Finland) was loaded in each agarose gel. The DNA bands were visualized on a UV transilluminator (BioView Ltd., Nes Ziona, Israel). The sensitivity of the $2 \mathrm{mPCR}$ assays was tested using a 2-fold serial dilution of the ATCC 9927 reference strain genomic DNA from $96 \mathrm{ng}$ to $1.5 \mathrm{pg}$. The PCR products obtained by the $2 \mathrm{mPCR}$ assays were analyzed and quantified using the Agilent BioAnalyzer 
Table 1. Multiplex PCR primers used in this study, including gene targets, amplicon size, primer sequences (For, forward; Rev, reverse), and gene sequence accession numbers

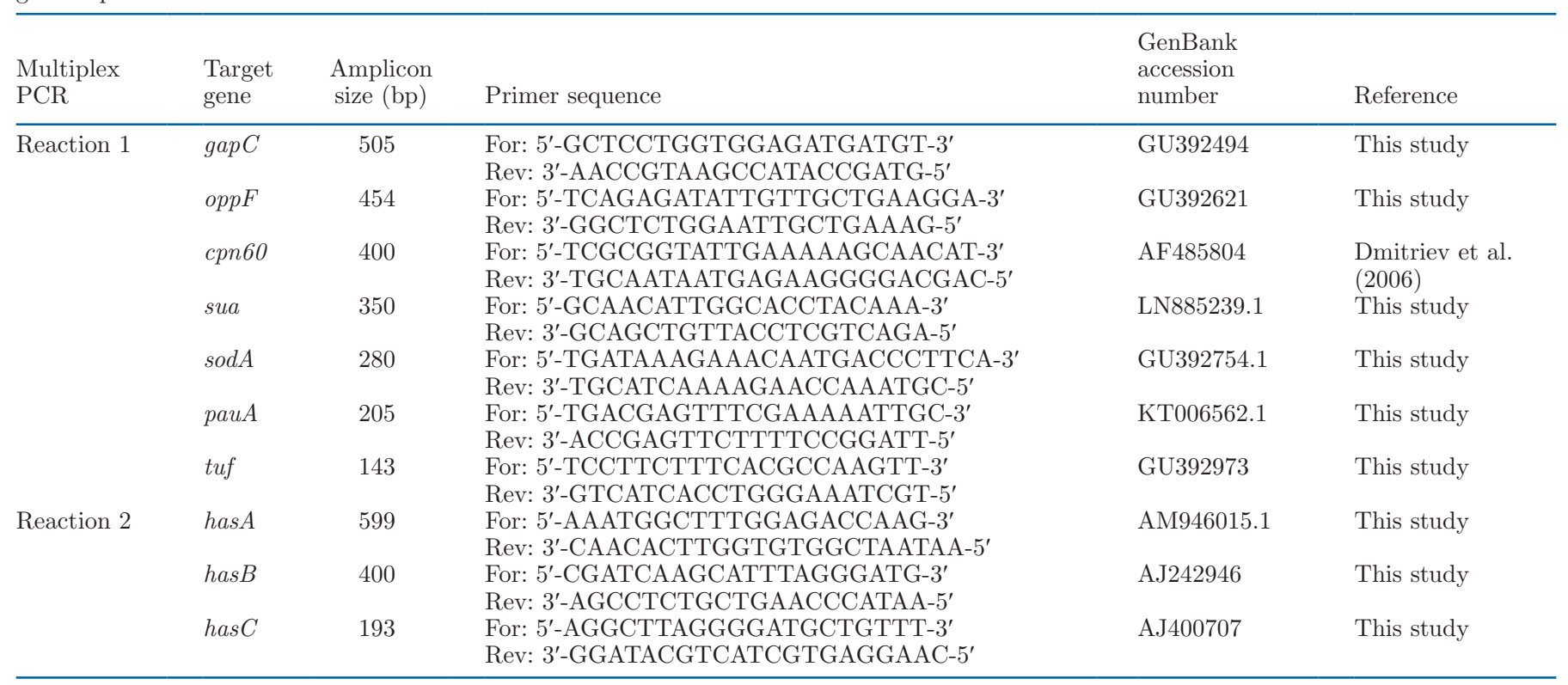

2100, applying the DNA 500 LabChip kit (Agilent Technologies, Palo Alto, CA).

Using the ATCC reference strain, the mPCR assays were successfully optimized and the desired amplicons were obtained in both reactions, as shown in Figure 1. In reaction 1, 7 bands with sizes of $505,400,369$, 350, 280, 205, and $143 \mathrm{bp}$, corresponding to gapC, oppF, сpn60, sua, sodA, pauA, and tuf genes, were distinguished without interactions among them, (Figure $1 \mathrm{~A})$. In reaction 2,3 bands with sizes of 599,400 , and 193 bp were obtained, corresponding to has $A$, hasB, and has $C$ genes, respectively (Figure 1B). As shown in lane 1 (Figure 1A and 1B), the primer concentrations used in the single reaction resulted in approximately equal yields for all amplification products. To check the assays' sensitivity and verify similar results between multiplex and simplex PCR, 2-fold serial dilutions were tested starting from the Strep. uberis ATCC 9927 genomic DNA reference strain. The sensitivity of the 2 mPCR assays was 23.5 and $11.8 \mathrm{pg}$, for mPCR 1 and mPCR2, respectively, corresponding to approximately $20 \mathrm{cfu} / \mathrm{mL}$ for both reactions (Figure 2), which confirms that the standardized assays allowed amplification of all putative and known virulence-associated genes of Strep. uberis. The limit of detection (LOD) of the 2 mPCRs developed in this work was comparable to those of previous studies. For example, Wang and Liu (2015) optimized a loop-mediated isothermal amplification (LAMP)-PCR for mastitis pathogens, including Strep. uberis, with an LOD of $0.1 \mathrm{pg}$ of DNA. Phuektes and coworkers (2001) reported an LOD of $50 \mathrm{pg}$ for their mPCR assay to identify Strep. uberis, whereas Shome et al. (2011) improved the sensitivity of an mPCR assay for the detection of mastitis pathogens including Strep. uberis and reached an LOD of $10 \mathrm{fg}$.

All 56 Strep. uberis isolates harbored at least one virulence-associated gene and all were positive for tuf, sodA, and cpn60 genes. The MPCR assays detected the $g a p C$ and oppF genes in $98.2 \%$ of the strains, whereas the sua gene was found in 53 strains $(94.6 \%)$. These virulence genes were commonly detected among the Strep. uberis strains, as previously described (Reinoso et al., 2011; Parin et al., 2017; Boonyayatra et al., 2018). The higher distribution of these genes among the Strep. uberis strains involved in clinical and subclinical mastitis is due to their role in Strep. uberis growth in milk (oppF; Smith et al., 2002) or to their involvement in virulence ( gapC and sua genes; Boonyayatra et al., 2018).

The has $C$, has $A$, and hasB genes were detected in 50 $(89.2 \%), 48(85.7 \%)$, and $47(83.9 \%)$ isolates, whereas the pauA gene was detected in $45(80.3 \%)$ isolates. These results concur with previous studies (Reinoso et al., 2011; Boonyayatra et al., 2018) that reported a higher frequency of hasC than of has $A$ and hasB. As previously published by Reinoso et al. (2011) and Boonyayatra et al. (2018), differences in frequency among these 3 genes arise from the fact that the hyaluronic acid capsule (coded by hasABC genes) of Strep. uberis may not have a primary role in mammary gland 


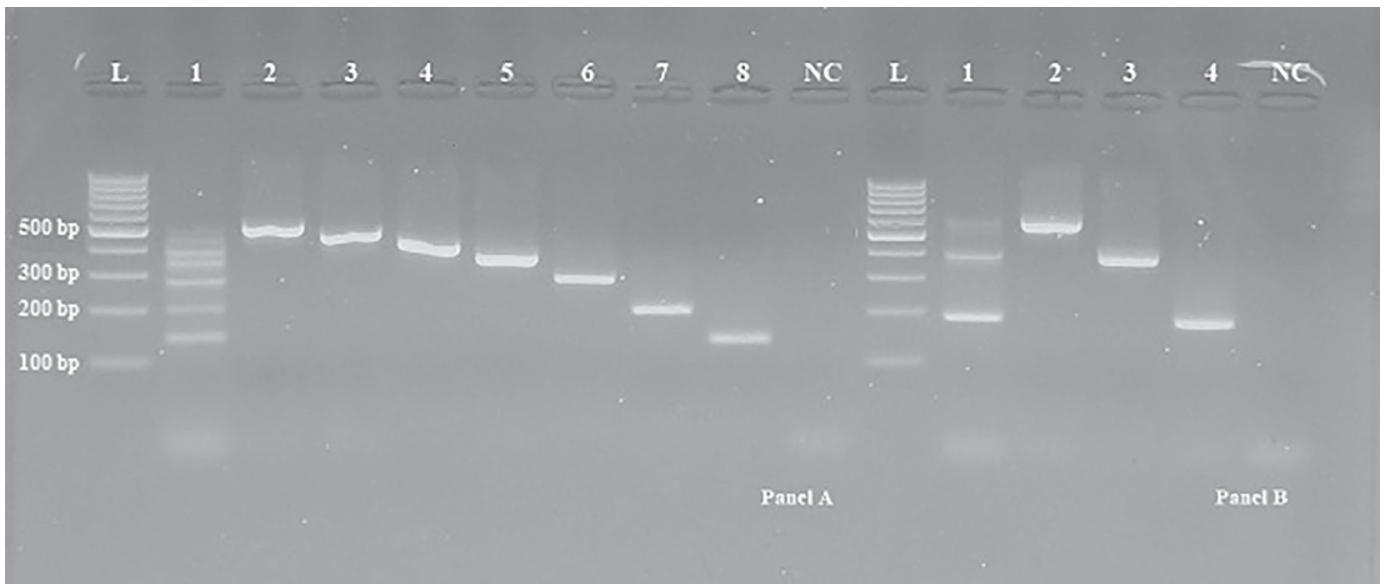

Figure 1. Optimization of multiplex (m)PCR reactions using genomic DNA of Streptococcus uberis ATCC 9927 strain. (A) Lane $1=$ mPCR 1 with all 7 genes; lanes 2-8 = uniplex PCR reactions for each gene: gapC (505 bp), oppF (454 bp), cpn60 (400 bp), sua (350 bp), sodA (280 bp), pauA (205 bp), tuf (143 bp), respectively; lane L: 100-bp DNA ladder; lane NC = negative control. (B) Lane $1=\mathrm{mPCR} 2$ with 3 genes; lanes 2-4 = uniplex PCR reactions for each gene: hasA (599 bp), hasB (400 bp), and hasC (193 bp), respectively; lane L = 100-bp DNA ladder; lane $\mathrm{NC}=$ negative control

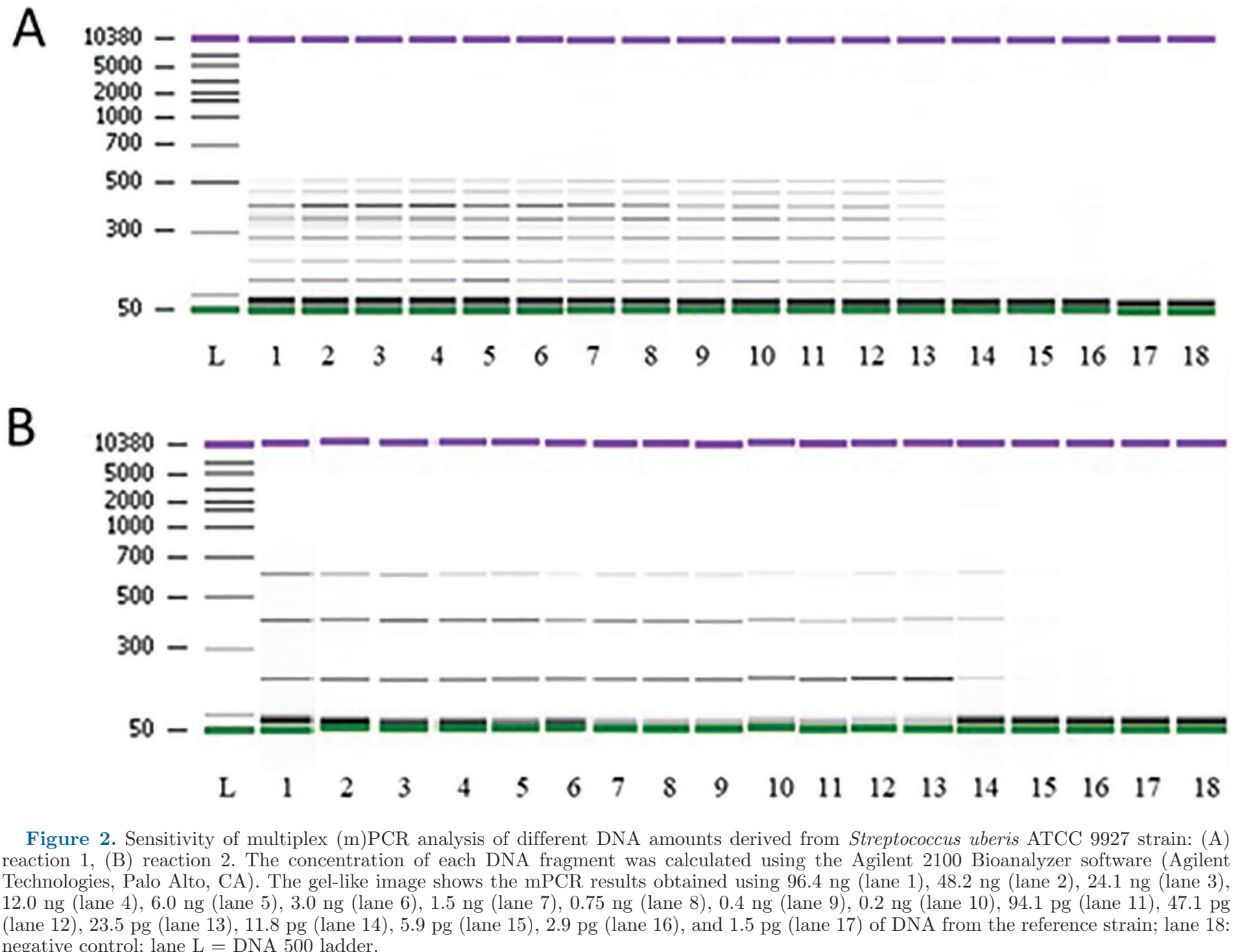


infection. Also, noncapsulated Strep. uberis isolates can induce mastitis by resistance to neutrophil phagocytosis (Field et al., 2003).

The distribution of virulence-associated genes revealed 12 virulence profiles, labeled A to $\mathrm{N}$ (Figure 3). The most common pattern was gapC+, oppF+, cpn60+, sua,$+ \operatorname{sod} A+$, pauA+, tuf,+ has $A+$, has $B+$, and has $C+$ (A profile) where cpn60, sodA, and tuf genes are housekeeping genes (Zadoks et al., 2005). Profile A included $59 \%(33 / 56)$ of isolates and was prevalent in $50 \%$ of the herds analyzed (6/12). The remaining $41 \%(23 / 56)$ of isolates were distributed in 11 profiles with $14 \%$ of isolates presenting pattern $\mathrm{B}(\mathrm{gap} C+$, opp $F+$, cpn $60+$, sua,$+ \operatorname{sod} A+$, tuf,+ has $A+$, has $B+$, has $C+; 7 \%)$ or $\mathrm{C}$
$($ gap $C+$, oppF+, сpn60+, sua+, sodA+, pauA+, tuft, $h a s B+, h a s C+; 7 \%)$. Although a small group of isolates was analyzed, our results showed a large genetic variability of Strep. uberis isolates, as previously published by Boonyayatra et al. (2018) and Reinoso et al. (2011) for 88 and 78 isolates, respectively. Some of these genes, such as sua, pauA, and gapC, encode virulence factors involved in the survival of the microorganism in the host environment, in its evasion of host tissue, and in its internalization in mammary gland cells, suggesting that isolates with pattern A could be more virulent and have a greater probability of causing mastitis (Reinoso et al., 2011; Boonyayatra et al., 2018). Further studies should be carried out on more isolates to reinforce

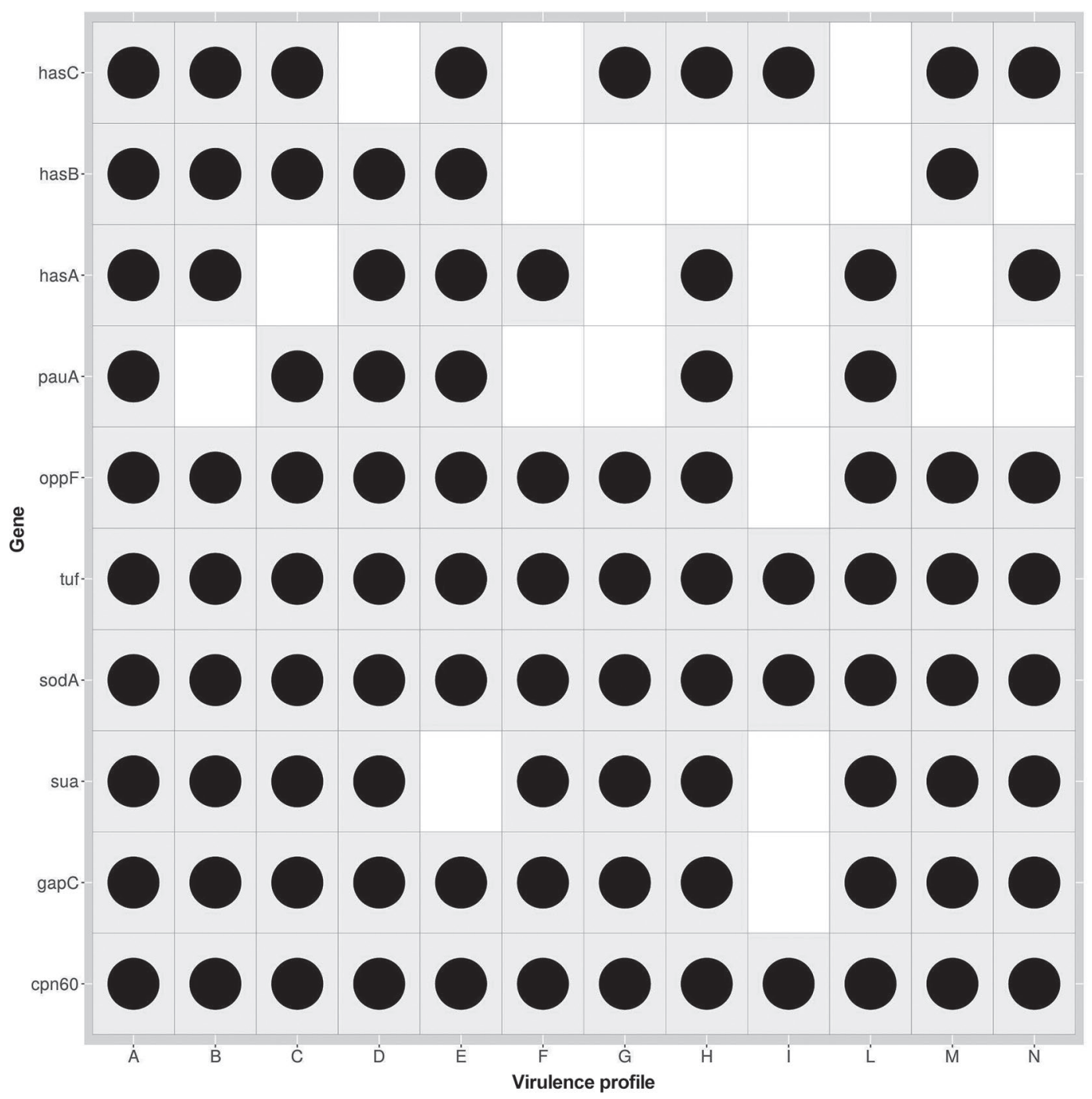

Figure 3. The distribution of genes investigated in virulence profiles. Each profile is indicated by letters from A to $\mathrm{N}$ and the presence of a given gene is shown by a black circle. Profile A was found in $59 \%$ of isolates (33/56); profiles B and $\mathrm{C}$ were found in $7.1 \%$ of the isolates (4/56); profile D was found in $5.4 \%$ of the isolates (3 out of 56); profiles E, F, G, and $\mathrm{H}$ were each found in $3.5 \%$ of the isolates (2/56); and profiles I, $\mathrm{L}, \mathrm{M}$, and $\mathrm{N}$ were each found in $1.7 \%$ of the strains $(1 / 56)$. 
these findings. Finally, to our knowledge, only a few studies have described mPCR assays for the molecular characterization of Strep. uberis strains (Parin et al., 2017; Boonyayatra et al., 2018). Boonyayatra et al. (2018) analyzed 11 genes in 3 different mPCR reactions that used 3 different annealing temperatures, whereas Parin et al. (2017), after species identification by the $16 \mathrm{~S}$ rRNA gene, detected 10 virulence genes in a single multiplex amplification reaction. They probably could not distinguish between the hasB and has $C$ virulence factors, because these 2 genes have amplification products of the same size (300 bp). The $\mathrm{mPCR}$ assays developed in the present study used some housekeeping genes - cpn60, soda, and tuf in order to unambiguously distinguish Strep. uberis from Strep. parauberis, a genetically closely related species, avoiding the need for any additional genotyping steps. It may be possible to analyze the same virulence genes, previously described, by reducing the time of analysis and the cost of the assay. These assays used only one amplification program, making the approach less costly and faster than previously described methods (Parin et al., 2017; Boonyayatra et al., 2018). This approach will potentially be very useful for the characterization of Strep. uberis in epidemiological studies, offering the ability to quickly obtain relevant information on the pathogenicity of isolates and progression of herd infections for a disease of growing concern.

\section{ACKNOWLEDGMENTS}

Filippo Biscarini is currently seconded to the European Research Council Executive Agency (ERCEA; Brussels, Belgium). The views expressed here are purely those of the writer and may not in any circumstances be regarded as stating an official position of the European Commission. The authors acknowledge Belinda Gross (Quality Milk Production Services, Animal Health Diagnostic Center, Cornell University, Ithaca, NY) for her valuable revision of the English text.

\section{REFERENCES}

Almeida, R. A., D. A. Luther, H. M. Park, and S. P. Oliver. 2006. Identification, isolation, and partial characterization of a novel Streptococcus uberis adhesion molecule (SUAM). Vet. Microbiol. 115:183-191.

Boonyayatra, S., P. Tharavichitkul, and S. P. Oliver. 2018. Virulenceassociated genes and molecular typing of Streptococcus uberis associated with bovine mastitis in northern Thailand. Turk. J. Vet. Anim. Sci. 42:73-81.

Bradley, A. J., K. A. Leach, J. E. Breen, L. E. Green, and M. J. Green. 2007. Survey of the incidence and aetiology of mastitis on dairy farms in England and Wales. Vet. Rec. 160:253-257.

Collado, R., C. Montbrau, M. Sitjà, and A. Prenafeta. 2018. Study of the efficacy of a Streptococcus uberis mastitis vaccine against an experimental intramammary infection with a heterologous strain in dairy cows. J. Dairy Sci. 101:10290-10302. https://doi.org/10 .3168/jds.2018-14840.

Cremonesi, P., B. Castiglioni, G. Malferrari, I. Biunno, C. Vimercati, P. Moroni, S. Morandi, and M. Luzzana. 2006. Technical note: Improved method for rapid DNA extraction of mastitis pathogens directly from milk. J. Dairy Sci. 89:163-169.

Dmitriev, A., M. Bhide, and I. Mikula. 2006. cpn60 gene based multiplex-PCR assay for simultaneous identification of streptococcal species. Acta Vet. Brno 75:235-240.

Field, T. R., P. N. Ward, L. H. Pedersen, and J. A. Leigh. 2003. The hyaluronic acid capsule of Streptococcus uberis is not required for the development of infection and clinical mastitis. Infect. Immun. $71: 132-139$

Gillespie, B. E., and S. P. Oliver. 2004. Comparison of an automated ribo-typing system, pulsed-field gel electrophoresis and randomly amplified polymorphic DNA fingerprinting for differentiation of Streptococcus uberis strains. Biotechnology (Faisalabad) 3:165-172.

Hassan, A. A., I. U. Khan, A. Abdulmawjood, and C. Lämmler. 2001. Evaluation of PCR methods for rapid identification and differentiation of Streptococcus uberis and Streptococcus parauberis. J. Clin. Microbiol. 39:1618-1621.

Krömker, V., N. T. Grabowski, and J. Friedrich. 2014. New infection rate of bovine mammary glands after application of an internal teat seal at dry-off. J. Dairy Res. 81:54-58. https://doi.org/10 $.1017 /$ S0022029913000599.

Liang, D., L. M. Arnold, C. J. Stowe, R. J. Harmon, and J. M. Bewley. 2017. Estimating US dairy clinical disease costs with a stochastic simulation model. J. Dairy Sci. 100:1472-1486. https://doi.org/10 .3168/jds.2016-11565.

Loures, R. A., U. D. Pereira, G. D. de Carvalho-Castro, G. F. Mian, D. A. D. Custodio, J. R. da Silva, and G. M. da Costa. 2017. Genetic diversity and virulence genes in Streptococcus uberis strains isolated from bovine mastitis. Semin. Cienc. Agrar. 38:2595-2605. https://doi.org/10.5433/1679-0359.2017v38n4Supl1p2595.

National Mastitis Council. 2017. Laboratory Handbook on Bovine Mastitis. National Mastitis Council, New Prague, MN.

Pancholi, V., and V. A. Fischetti. 1993. Glyceraldehyde-3-phosphate dehydrogenase on the surface of group A streptococci is also an ADP-ribosylating enzyme. Proc. Natl. Acad. Sci. USA 90:81548158.

Parin, U., S. Kirkan, E. Cicek, and H. T. Yuksel. 2017. Detection of virulence genes in Streptococcus uberis isolated from bovine mastitis in Aydin province by multiplex polymerase chain reaction. F. Ü. Să̆. Bil. Vet. Derg. 31:213-219.

Perrig, M. S., M. B. Ambroggio, F. R. Buzzola, I. S. Marcipar, L. F. Calvinho, C. M. Veaute, and M. S. Barbagelata. 2015. Genotyping and study of the pauA and sua genes of Streptococcus uberis isolates from bovine mastitis. Rev. Argent. Microbiol. 47:282-294. https://doi.org/10.1016/j.ram.2015.06.007.

Phuektes, P., P. D. Mansell, and G. F. Browning. 2001. Multiplex polymerase chain reaction assay for simultaneous detection of Staphylococcus aureus and streptococcal causes of bovine mastitis. J. Dairy Sci. 84:1140-1148.

Pullinger, G. D., M. Lopez-Benavides, T. J. Coffey, J. H. Williamson, R. T. Cursons, E. Summers, J. Lacy-Hulbert, M. C. Maiden, and J. A. Leigh. 2006. Application of Streptococcus uberis multilocus sequence typing: Analysis of the population structure detected among environmental and bovine isolates from New Zealand and the United Kingdom. Appl. Environ. Microbiol. 72:1429-1436.

Reinoso, E. B., M. C. Lasagno, S. A. Dieser, and L. M. Odierno. 2011. Distribution of virulence-associated genes in Streptococcus uberis isolated from bovine mastitis. FEMS Microbiol. Lett. 318:183-188. https://doi.org/10.1111/j.1574-6968.2011.02258.x.

Reinoso, E. B., M. C. Lasagno, and L. M. Odierno. 2015. Genetic patterns of Streptococcus uberis isolated from bovine mastitis. Rev. Argent. Microbiol. 47:108-111. https://doi.org/10.1016/j.ram .2015.02.001.

Rosey, E. L., R. A. Lincoln, P. N. Ward, R. J. Yancey Jr., and J. A. Leigh. 1999. PauA: A novel plasminogen activator from Streptococcus uberis. FEMS Microbiol. Lett. 178:27-33. 
Shome, B. R., S. Das Mitra, M. Bhuvana, N. Krithiga, D. Velu, R. Shome, S. Isloor, S. B. Barbuddhe, and H. Rahman. 2011. Multiplex PCR assay for species identification of bovine mastitis pathogens. J. Appl. Microbiol. 111:1349-1356. https://doi.org/10.1111/ j.1365-2672.2011.05169.x.

Smith, A. J., A. J. Kitt, P. N. Ward, and J. A. Leigh. 2002. Isolation and characterization of a mutant strain of Streptococcus uberis, which fails to utilize a plasmin derived beta-casein peptide for the acquisition of methionine. J. Appl. Microbiol. 93:631-639.

Tassi, R., T. N. McNeilly, J. L. Fitzpatrick, M. C. Fontaine, D. Reddick, C. Ramage, M. Lutton, Y. H. Schukken, and R. N. Zadoks. 2013. Strain-specific pathogenicity of putative host-adapted and nonadapted strains of Streptococcus uberis in dairy cattle. J. Dairy Sci. 96:5129-5145. https://doi.org/10.3168/jds.2013-6741.

Wang, D., and Y. Liu. 2015. Development of primer sets for loopmediated isothermal amplification that enables rapid and specific detection of Streptococcus dysgalactiae, Streptococcus uberis add Streptococcus agalactiae. Int. J. Environ. Res. Public Health 12:5735-5742. https://doi.org/10.3390/ijerph120605735.
Ward, P. N., T. R. Field, W. G. Ditcham, E. Maguin, and J. A. Leigh. 2001. Identification and disruption of two discrete loci encoding hyaluronic acid capsule biosynthesis genes has $A$, hasB, and has $C$ in Streptococcus uberis. Infect. Immun. 69:392-399.

Wieliczko, R. J., J. H. Williamson, R. T. Cursons, S. J. Lacy-Hulbert, and M. W. Woolford. 2002. Molecular typing of Streptococcus uberis strains isolated from cases of bovine mastitis. J. Dairy Sci. $85: 2149-2154$.

Yuan, Y., O. K. Dego, X. Chen, E. Abadin, S. Chan, L. Jory, S. Kovacevic, R. A. Almeida, and S. P. Oliver. 2014. Short communication: Conservation of Streptococcus uberis adhesion molecule and the sua gene in strains of Streptococcus uberis isolated from geographically diverse areas. J. Dairy Sci. 97:7668-7673. https:// doi.org/10.3168/jds.2013-7637.

Zadoks, R. N., L. L. Tikofsky, and K. J. Boor. 2005. Ribotyping of Streptococcus uberis from a dairy's environment, bovine feces and milk. Vet. Microbiol. 109:257-265. 